\title{
LO LOCAL, LO GLOBAL, LO COTIDIANO DEL LATINO: UNA MIRADA A LA CAMPAÑA PRESIDENCIAL DE OBAMA Y CLINTON
}

\section{LOCAL, GLOBAL, EVERYDAY OF AMERICA: A LOOK AT THE PRESIDENTIAL CAMPAIGN OF OBAMA AND CLINTON}

\section{AUTOR/ES}

María Elena del Valle de Villalba: Profesora Ordinaria de la Universidad Pedagógica Experimental Libertador. Investigadora acreditada del CYET. Caracas. (Venezuela)

manedelvalle@gmail.com

Jorge Portilla Enríquez: Profesor de la Universidad Autónoma Metropolitana. Caracas (Venezuela) jportilla@unimet.edu.ve portilla.jorge@gmail.com.

\section{RESUMEN}

Este trabajo presenta el análisis de un material videográfico que compone la campaña presidencial de Hillary Clinton y Barack Obama dirigida a conquistar el voto latino. A través del método etnográfico (Martínez, 1994) se realiza el análisis de los estereotipos de latino presentados en los videos y se interpreta la descripción de los grupos a los cuales está dirigida la campaña, desde la presentación de lo local, lo cotidiano y la imagen globalizada del latino en dichos videos. Se seleccionaron para este estudio una muestra de dos videos de cada candidato y se procedió a la aplicación de la técnica estudio de caso (Velazco y Díaz, 1997) explicando, desde los aportes de Bourdieu (1990), el papel de los medios en las audiencias actuales para la conformación del mundo social, la percepción de grupos sociales y suposiciones compartidas. Para el análisis del contenido verbal se hace referencia a los trabajos de Ernesto Laclau.

\section{PALABRAS CLAVE}

Voto Latino - Medios de comunicación - Estereotipos. 
This article deals with an analysis of different kind of material (videos, slogans, songs...), which is part of Hillary Clinton and Barack Obama campaign to achieve the Latin vote. Through the ethnographic method (Martínez, 1994) we will analyse and interpret the different stereotypes showed in the mentioned material, from the presentation of local, daily and globalized image of the Latin people who appear in the videos. In order to complete this study, it has been selected a sample of two videos (per candidate) and it has been put into practice a case study technique (Velazco y Díaz, 1997). We will explain, basing on Bourdieu ideas (1990), the role of the media in actual audiences to conform the social world, the social group's perception and shared suppositions. On the other hand, for the analysis of verbal content we will refer to Ernest Laclau works.

\section{KEY WORDS}

Latin vote - Media - Stereotypes.

ÍNDICE

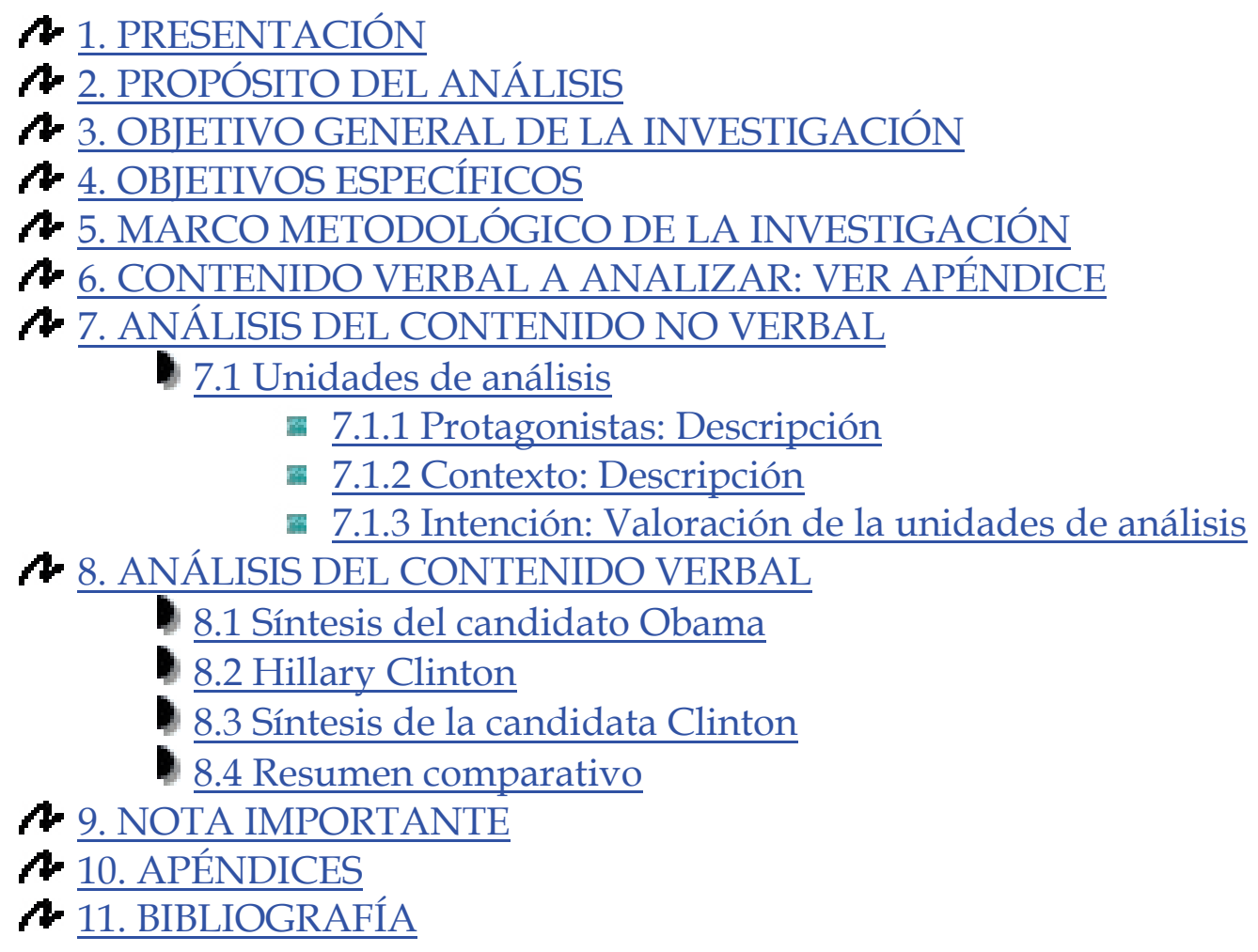

\section{PRESENTACIÓN}

En la sociedad contemporánea los discursos verbales y no verbales cumplen papeles determinantes. En el caso específico de las imágenes, las mismas pueden crear y 
recrear representaciones sociales. Modelos, estereotipos, actores, van haciendo sincretismo sistemático cuando al presentarse con cierta regularidad legitiman, advierten, definen y caracterizan papeles a ser jugados dentro de la sociedad. En el caso que nos ocupa, el material videográfico que conforman el corpus a ser analizado presenta una imagen concreta de "latino" como grupo social. Ambos candidatos por el partido demócrata a la presidencia de los Estados Unidos, generaron un material videográfico que intenta, en su propuesta conquistar la atención e intención de voto del "latino".

Ese "latino" como grupo social definido pero ambiguamente constituido se presenta en los videos de una manera concreta. La imagen como proceso interactivo genera en los videos la relación de un conjunto de ínter subjetividades en las que los actores presentados, son definidos y nombrados, envueltos en un conjunto de características que los definen como grupo. El interés de este acercamiento desde la semiótica visual de dichos materiales, es caracterizar qué imagen de "latino" se presenta y qué atributos se le adjudican, asumiendo que los "latinos" como grupo social específico están conformados por un conjunto de personas de diversas nacionalidades: mexicanos, colombianos, portorriqueños, cubanos entre otros, que son envueltos y definidos por el video como un solo grupo.

\section{PROPÓSITO DEL ANÁlISIS}

Desde la perspectiva de la antropología y la semiótica visual, la experiencia de observar este video genera procesos cognitivos complejos y abre horizontes analíticos desde los cuales se ilustra la vida cotidiana, lo local y lo definitorio del "latino" en Estados Unidos. Dichos atributos no pueden abordarse sólo desde la descripción sino que debe perseguirse la interpretación de lo allí presentado, valorando las ínter subjetividades, partiendo del supuesto de que el director/a del material videográfico en la medida en que selecciona las imágenes, lo hace desde una concreta intencionalidad.

Lorenzo Vilches ${ }^{1}$ introduce desde sus aportes la observación de las imágenes como textos, es decir, susceptibles de leerse y por lo tanto interpretarse de formas específicas. La función comunicativa de los signos y su presentación de actores y objetos involucran un abordaje desde la pragmática, es decir la interpretación, el objetivo que se persigue al hacer esa presentación y los efectos en la formación de conceptos sociales.

En el material videográfico a ser analizado se usan tanto el lenguaje verbal como el no verbal ya que las imágenes son acompañadas por canciones que van concretando significados. La palabra a decir de Roca ${ }^{2}$ no es parásita de la imagen, sino su realizadora, ya que la imagen es más abstracta que la palabra. De tal manera, si asumimos que la palabra genera efectos polisémicos, la imagen los generará en mayor número y 
profundidad. Imagen y palabra se presentan en el material videográfico seleccionado contribuyendo a la creación y recreación del concepto de "latino" en los observadores.

¿Qué imagen se presenta del "latino" en los materiales seleccionados? ¿A qué atributos se le asocia? ¿Qué funciones sociales se les atribuye? ¿Qué elementos de orden ideológico se encuentran presentes en el material? ¿Qué papel se le otorga a los géneros femenino y masculino? Son algunas de las preguntas a las que se les da respuesta en este estudio.

\section{OBJETIVO GENERAL DE LA INVESTIGACIÓN}

Realizar la interpretación desde la semiótica ${ }^{3}$ y antropología visual ${ }^{4}$ de los elementos verbales y no verbales presentados en el material videográfico producido por el comando de campaña electoral de Barack Obama y Hillary Clinton para la conquista del voto "latino".

\section{OBJETIVOS ESPECÍFICOS}

Analizar el contenido verbal y no verbal del material videográfico producido por el comando de campaña electoral de Barack Obama.

Analizar el contenido verbal y no verbal del material videográfico producido por el comando de campaña electoral de Hillary Clinton.

Interpretar desde la antropología y la semiótica visual las implicaciones de los contenidos verbales y no verbales del material videográfico seleccionado.

\section{MARCO METODOLÓGICO DE LA INVESTIGACIÓN}

El enfoque metodológico desde el cual se aborda esta investigación es el etnográfico ${ }^{5}$ ya que se persigue el análisis de la percepción de un grupo social, "latino" no limitándose a la ilustración de las imágenes con palabras, sino que busca la deconstrucción del proceso sociocultural de las experiencias visuales particulares es decir, la interpretación de lo local, lo cotidiano, lo global del grupo: "latino" que se presenta en el material videográfico escogido. 
Se seleccionaron dos muestras de material videográfico, una de cada candidato, cuyas letras fueron transcritas para su posterior análisis. El material videográfico fue observado por los dos investigadores, primero de manera individual, sin guión de unidades de análisis y luego de haber establecido los elementos a observar, se realizó la observación conjunta del material.

Se utilizó para el análisis del material videográfico la denominada concepción amplia de Padrón, quién concibe como componentes de la comunicación semiótica a los protagonistas, el contexto, la intención y los significados. ${ }^{6}$

Las letras de las canciones que acompañan el material se analizaron en función de las siguientes categorías a observar:

- Papeles o roles representados

- Representación de lo local

- Contenido ideológico

- Variantes lingüísticas

\section{CONTENIDO VERBAL A ANALIZAR: VER APÉNDICE}

\section{ANÁLISIS DEL CONTENIDO NO VERBAL}

\subsection{UNIDADES DE ANÁLISIS}

\subsubsection{PROTAGONISTAS: DESCRIPCIÓN}

Los atributos identificados en la presentación de la categoría: protagonistas, son los mismos en ambas propuestas, salvo en el material que lleva por título: “Oye, Oye, Oye, Hillary", en donde la mayoría de las protagonistas son mujeres.

\section{Hombres:}

En ambas propuestas los hombres latinos son presentados a través de estereotipos de la minoría latina: cantantes de reggaetón, charros, con la apariencia de cantantes de rap, cada uno de ellos con la carga despectiva que es apuntalada por los medios de comunicación. 


\section{Mujeres:}

En ambas propuestas la mujer es presentada desempeñando roles de obrera, cocinera, lavandera, siempre en obvia dependencia o inferioridad con respecto a la figura del candidato/a, sumisa, desvalida en espera de ayuda.

\section{Candidatos:}

En obvia superioridad, siempre en actitud de consuelo y auxilio. Abrazando, acariciando a los niños. Usando los atuendos folklóricos de algunos grupos de latinos: sombreros, trajes o chaquetas.

\section{Niños:}

Generalmente ataviados con trajes típicos (charro). Se les presenta como pacientes en las clínicas o tomados de la mano de los candidatos.

\section{Banderas:}

Son considerados como un personaje más de la propuesta ya que su presentación es repetida y constante en el material videográfico de ambos candidatos. Las banderas presentes son las de México y Cuba, haciéndose énfasis en el águila de la bandera de México.

\subsubsection{CONTEXTO: DESCRIPCIÓN}

Los contextos en los cuales se desarrollan las acciones en los videos son:

- El barrio latino, con las típicas construcciones y colorido de los mismos.

- Lugares donde se llevan a cabo prácticas folklóricas como "derribar la piñata", se canta reggaetón, o se entonan rancheras.

- Patios y jardines que son atendidos por los protagonistas, construcciones, talleres mecánicos, lavanderías, comederos o fuentes de soda.

\subsubsection{INTENCIÓN: VALORACIÓN DE LAS UNIDADES DE ANÁLISIS}

La creación de estereotipos es una herramienta mental-cognitiva que permite la comprensión de realidades diversas, su categorización y comunicación. Este "latino" surge en el material como representación única de ese "otro" diferente a la cultura norteamericana dominante. Se utiliza aquí la palabra "latino" para designar, como se 
hace en los Estados Unidos de América, a las persones provenientes de América Latina, de manera simple y poco profunda. Es obvia la gran diferencia entre mexicanos y argentinos o cubanos y chilenos, tanto a nivel colectivo como individual sin embargo en el material videográfico no se hace diferenciación alguna.

La representación de los "latinos" es estereotipada, entendiendo por estereotipo: las imágenes mentales negativas o positivas que tenemos de otros grupos, siendo en este caso concreto imágenes negativas ya que no resaltan la potencialidad y las capacidades obvias de este grupo social que han llevado a los candidatos a tomarlos en cuenta como fuerza de voto. A este respecto afirma Weber:

Diferencias en la barba y el cabello, vestido, modo de alimentarse, división del trabajo entre los sexos y todas las demás que saltan a la vista, pueden dar pie en algunas casos a atracción o repulsión entre gentes diferentes $\mathrm{y}$, como reverso positivo, a la conciencia de comunidad entre gentes parecidas. ${ }^{7}$

No es difícil asociar las representaciones de la cotidianidad latina con elementos peyorativos al hacer esa específica presentación de los barrios donde habitan. Así mismo, la representación del trabajo que realizan los "latinos" en el material videográfico y los roles a los cuales estos son asociados no reflejan las patentes capacidades del grupo "latino". Los papeles representados por los protagonistas del material son retratados en posición de evidente asimetría, ocupacional, aptitudinal y social. Los oficios y ocupaciones se asocian a niveles bajos de complejidad y remuneración, característica que se cumple tanto en la presentación de hombres como de mujeres.

El elemento folklórico es usado en exceso y de manera superficial quedándose solo en lo externo de las minorías representadas (el traje de charro, las piñatas, la guitarra, etc.). En este caso en particular se puede afirmar que la presentación estereotipada del "latino" dice más acerca de los que los elaboran, difunden y los hacen suyos, (en este caso ambos candidatos), que de las personas o grupos estereotipados. Hablan más de cómo ven a los "latinos" desde su subjetividad, que de cómo son los "latinos".

El estereotipo cumple en este caso una función identitaria, al representar de manera distorsionada y parcial lo que los "latinos" significan cultural, étnica y cotidianamente. El material videográfico dibuja un mini-mundo "latino" que no le hace justicia a sus potencialidades y características reales. La pregunta obligada sería: ¿Cómo cala en este grupo este material? ¿Pueden sentirse interpretados y definidos: argentinos, mexicanos, peruanos, puertorriqueños, venezolanos, por esta imagen tan vaga, peyorativa y general? ¿Puede sentirse respetado como votante un "latino" al que se le muestra este material? ¿Qué se asocia a los latinos? ¿Eso (lo presentado en el material) los define? Se trata de la conjugación de los siguientes procesos: cómo nos vemos, cómo nos ven, cómo les vemos,

\footnotetext{
7 Weber 317.
} 
cómo se ven, que en apariencia van en direcciones distıntas pero que en el material videográfico se conjugan describiendo de manera cruda, cómo ven al “latino" y cómo el "latino" ve la cultura norteamericana.

Si como dice Hall ${ }^{8}$ la identidad es un proceso en continua formación, nunca estática o fija en un tiempo histórico, sin duda el material hace una fotografía de la concepción de "latino" que poseen quienes lo elaboran. Los seres y grupos humanos construyen y deconstruyen permanentemente las identidades en un proceso cuyo eje central pasa a ser la relación con el otro, por lo que es a través de la diferenciación respecto del otro, como logramos construir nuestra propia existencia. Está claro que hay un "nosotros" y un "ellos" representados en la cultura dominante norteamericana y el "latino" dibujado en el material. La pregunta finalmente es: si ¿como "latinos" se responderá a este material y de qué manera se hará? Si el material cala en el grupo ¿qué dice esto de él?

\section{ANÁLISIS DEL CONTENIDO VERBAL}

Coincidiendo con Yves Meny e Ives Surel, Ernesto Laclau sostiene que no hay política que no posea algún matiz populista. ${ }^{9}$ El populismo -continúa- es una cuestión de grado, de la proporción en que las lógicas equivalenciales ${ }^{10}$ prevalecen sobre las diferenciales. ${ }^{11}$

Se ha dicho ${ }^{12}$, que en los trabajos de Laclau puede apreciarse que el populismo es, al mismo tiempo, tanto un objeto de investigación, como el nódulo de una reflexión crítica sobre la lógica de las identidades sociales y la política. Según las mismas fuentes, este autor es uno de los primeros investigadores en romper con la tradición que sitúa el populismo como una categoría residual y subordinada del análisis político. Para él, el populismo no es un fenómeno marginal de la experiencia política sino, por el contrario, es una vía para comprender la política y especialmente la contemporánea. ${ }^{13}$

Laclau afirma que lo fundamental no es encontrar el verdadero referente del populismo, ni las condiciones subjetivas y objetivas que hacen posible su emergencia: considera que lo más importante es mostrar que el populismo trata de una lógica social cuyos efectos atraviesan una variedad de fenómenos. Para él, la génesis del proceso político está en la construcción de las identidades políticas, y la formación de identidades

\footnotetext{
8 Hall.

${ }^{9}$ Laclau (2006) 57. Cita a Meny Yves y Surel Ives (2000). Pour le peuple, par le peuple. Fayard: Paris.

${ }^{10}$ Lo "equivalencial" en Laclau comprende una categoría de procesos o lógicas que contribuyen a la formación de identidades.

${ }^{11}$ Laclau (2006) 58.

${ }^{12}$ Patruyo 169.

${ }^{13}$ Patruyo 169.
} 
es de naturaleza discursiva. ${ }^{14}$ Las estructuras discursivas no son entidades meramente cognoscitivas o contemplativas, son prácticas articulatorias que constituyen y organizan a las relaciones sociales. ${ }^{15}$

Exorcizado así el populismo, podemos abordar con más serenidad los textos de las dos piezas musicales en los que se basa nuestro estudio y cuyo contenido, convenimos, es fuertemente populista. No vamos a escandalizarnos entonces, ni hacer comentarios cínicos o expresar nuestra decepción de que se pretenda ganar la voluntad de los hispanoamericanos ("hispanos", simplemente, para los norteamericanos que al apropiarse del término genérico "americano", no pueden concatenarlo al de "hispano" sin hacer fuertes concesiones, por lo menos, nacionales) con recursos, diríamos, tan básicos.

Pero no vamos a dejar pasar, por apropiada, la convicción de Laclau de que cuando se tiene una sociedad altamente institucionalizada, $-y$ ese es el caso de la norteamericana- las lógicas equivalenciales tienen menos terreno para operar $\mathrm{y}$, como resultado, la retórica populista se convierte en una mercancía carente de toda profundidad hegemónica. En este caso, sí, el populismo se vuelve casi sinónimo de demagogia trivial. ${ }^{16} \mathrm{Y}$ ese es nuestro punto: ambas piezas pueden encuadrarse en una demagogia trivial. No puede haber profundidad hegemónica para los latinos y por ello, los textos no se comprometen ofreciéndola. Por otra parte, tan demarcado es el carácter de mercancía, que la estructura de ambas canciones utiliza mecanismos más propios de la publicidad comercial (advertising) más que de la propaganda política.

Por otra parte, Laclau expresa:

Llamaremos articulación a cualquier práctica que establece una relación entre los elementos tal que la identidad de ellos se modifica como resultado de la práctica articulatoria. Llamaremos discurso a la totalidad estructurada que es el resultado de la práctica estructurada. Llamaremos momentos a las posiciones diferenciales, en la medida en que aparecen articuladas dentro de cualquier discurso. Por contraste, llamaremos elemento a cualquier diferencia que no se articula discursivamente. ${ }^{17}$

\footnotetext{
${ }^{14}$ Patruyo 170.

${ }^{15}$ Patruyo 171. La autora cita a Laclau Ernesto (1987). "Populismo y transformación del imaginario político en América Latina", Boletín de Estudios Latinoamericanos y del Caribe, no 42, pp. 25-38, p. 109.

${ }^{16}$ Laclau (2005) 238.

${ }^{17}$ Laclau (1985) 105. We will call articulation any practice establishing a relation among elements such that their identity is modified as a result of the articulatory practice. The structured totality resulting from the articulatory practice, we will call discourse. The differential positions, insofar as they appear articulated within any discourse, we will call moments. By contrast, we will call element any difference that is not discursively articulated.
} 
Bajo la intluencia de estas proposiciones de Laclau, vamos a etectuar un análisis minucioso de los textos, pero alterando de algún modo tales propuestas. En efecto, vamos a elaborar un modelo semántico (el texto y los referentes asociados se encuentran en ese dominio) donde buscaremos lo que entendemos es característico de los momentos de un discurso político, populista o no, degradado o no a mero reclame comercial:

1. Un aspecto identificatorio o aglutinatorio respecto a algún objeto o sujeto para entes del mismo grupo.

2. Un aspecto diferencial, que se desprende como consecuencia de la identificación anterior, el cual:

2.1 Diferencia a los entes identificados o aglutinados de entes de grupos rivales.

2.2 Diferencia a los entes identificados o aglutinados de entes del mismo grupo.

Comenzaremos por el candidato Barack Obama, luego por la señora Hillary Clinton e intentaremos una comparación entre ambos.

Texto publicado, sin el título es de 190 palabras, pero un conteo de lo cantado arroja un valor de unas 237 palabras en virtud de las repeticiones. El vocabulario es de 87 términos relativamente básicos, pero que se repiten mucho: $118,39 \%$ es la ratio texto sobre vocabulario.

El efecto apuntado en el párrafo anterior nos conduce a la noción de recalling, perfectamente estudiado en publicidad. Consiste en repetir el nombre, normalmente la marca, varias veces para que se retenga en la memoria. Así, es común en un aviso comercial de 30 segundos que la marca se repita no menos de seis veces. De ese modo, cuando el ama de casa transita por los pasillos de un supermercado y es bombardeada por los atrayentes empaques de los productos, cuando percibe la marca que lleva en su memoria es muy posible que la coloque en su carrito de compras. ¡Nada más platónico que esto: conocer es recordar! ¡Procter \& Gamble@ o Palmolive $@$, reminiscencias del тónos oủpavós!

Aproximadamente 46\% (108 palabras repetidas de 5 sobre 237) del reggaetón está dedicado al recalling. De ese porcentaje, el nombre del candidato es el 37\%, es decir, el $16,88 \%$ de toda la pieza. De las 20 ocurrencias de nombres ${ }^{18}$, el 60,61\% del 100\% de estas, corresponde al nombre del candidato.

${ }^{18} \mathrm{El} \mathrm{27,85 \%}$ del texto. 
Cuando se aprecia que de los 21 verbos activos (prácticamente, todos los verbos son activos) empleados en el texto en 59 ocurrencias ${ }^{19}$ está ligado a la acción. Diez de esas ocurrencias (16,95\%) corresponden al verbo "votar", puede argumentarse con bastante certeza que el discurso textual tiene un carácter preformativo o illocucionario (à la John Langshaw Austin), estructurado sobre conceptos de marketing comercial. Si agregamos a ello el carácter popular en la población latinoamericana joven y urbana ${ }^{20}$ del género musical utilizado, el reggaetón, originario de Panamá a finales de la década de 1980 o comienzos de la de 1990 (Marshall McLuhan hubiese estado feliz), podemos agregar a las precisiones anteriores el carácter de populista. ¿Recordamos la demagogia trivial que denunciaba Laclau?

Como es de esperarse, la adjetivación es pobre: 10 ocurrencias, 4,22\% del texto.

La temporización del discurso se concentra mayoritariamente en el presente en una explicitación del "aquí" y "ahora". El pasado está mínimamente representado (did), en spanglish y vinculado a los potenciales electores, no al candidato que parece no tener historia que contar en ese sentido. Igualmente el futuro, localizado en el verbo "ir": esto va a cambiar. Sólo una promesa abierta, indefinida.

El empleo del spanglish se verifica en las siguientes frases.

- We did the marchas.

- Listen to me gente. Me, suena fonéticamente como posesivo mi (se superponen, listen to me gente, escúchame gente y listen to $|\mathrm{mi}|$ gente, escucha a mi gente)

- What we need is un nuevo presidente.

Este aspecto es identificativo pues el metro de la versificación no requiere spanglish; tampoco la rima. Sí, tal vez, puede introducir algo de humor (si la mezcla de inglés y español en el habla popular lo produce). El humor está dado por transgresiones

\footnotetext{
${ }^{19} \mathrm{El} \mathrm{25 \%}$ del texto.
}

20 Para que no queden dudas, entre los inmigrantes latinoamericanos en los Estados Unidos hay técnico, científicos, académicos, artistas, etc., pero, como es de esperar no conforman la mayoría de los 9 millones de hispanos que son apetecidos por los políticos para que los apoyen con su voto. La gran mayoría corresponde a niveles de educación inferiores a la media norteamericana, inclusive a la media de poblaciones afro-descendientes. Según Susan Minushkin, Deputy Director del Pew Hispanic Center, de una muestra de 1809 hispanos, 21\% son menores de 30 años y 33\% entre 30 y 45 años (55\% sumados). Sólo el 10\% se concentra en áreas rurales. 65\% tienen más de high school vs. $81 \%$ de los blancos y $74 \%$ de los habitantes de raza negra. 12\% 3\% 5\% no finalizaron la high school, respectivamente. No obstante, el candidato Obama hace una segmentación: para su campaña en Texas, donde existe por razones históricas, incluso, un gran predominio de mexicanos, su jingle es una ranchera. 
en la pronunciación ("1unitorme" por unitorm o unitorme), juegos de palabras ("te llamo para atrás", por I call you back, te vuelvo a llamar), aplicación de elementos gramaticales, tales como morfemas, de una lengua en expresiones de la otra21 (corría fast-amente, por run fastly o corría rápidamente), intercambio de palabras u expresiones de la otra lengua en el discurso, etc. Estadísticamente, podemos decir, el spanglish corresponde al 4,22\% del texto y al 11,49\% del vocabulario.

El senador Obama desglosa el mundo hispano en ocho nacionalidades. Ellas son, en orden alfabético:

- Brasileños. ${ }^{22}$

- Colombianos. ${ }^{23}$

- Cubanos. ${ }^{24}$

- Dominicanos.

- Mexicanos. ${ }^{25}$

- Portorriqueños. ${ }^{26}$

- Peruanos.

- Salvadoreños.

Faltan importantes nacionalidades desde el punto de vista de su representación poblacional en los Estados Unidos como haitianos, hondureños, guatemaltecos, bolivianos, ecuatorianos, etc.

Sobre lo anterior intentamos construir una ontología semántica:

1. Entorno: Una gran nación.

\footnotetext{
${ }^{21}$ Algunos lingüistas, para negar la emergencia del spanglish como idioma, sostienen que las reglas de ambas lenguas confortantes se mantienen, lo cual es sólo parcialmente cierto en nuestra experiencia.

${ }^{22}$ Según Bernadete Beserra, los brasileños rechazan ser considerados latinos. Es posible que tal postura sea ignorada por los asesores de Obama o que no les interese si pueden llegar al corazón de, tal vez, unos 170.000 ilegales.

${ }^{23}$ Poseen una conexión con la droga.

${ }^{24}$ En gran proporción integrados a la sociedad norteamericana. Algunos poseen alto nivel de estudios y han podido alcanzar posiciones relativamente importantes.

${ }^{25}$ Son arquetípicos.

${ }^{26}$ Ciudadanos de un estado asociado.
} 
1.1 [Yero] ya es decir, en este momento) no existe una buena educación. Como lo que afecta al todo debe afectar a las partes, es posible que la educación no buena afecte a los latinos. El punto parece ser más complejo (ver 5.1.2.).

2 Actuantes.

2.1 Narrador/presentador

- Se identifica con los latinos.

- Acción: Ordena que le oigan (oye). Listen to me gente.

- Paciente de la acción: Los latinos (gente; su [mi] gente)

- Objeto a ser oído: La orden de votar por el candidato Obama.

2.2 Los latinos (18,18\% de los sustantivos; 5,06\% del discurso): (we y nosotros tácito), la gente [del narrador/presentador].

- Conforman un gigante. Y está “brotando". Parecería que ese brote es un despertar de no ser porque a continuación el narrador/presentador los conmina a que despierten: “¡Despierta!”

- Nacionalidades (particularización; reducción de problemas para cada nacionalidad. Por ejemplo, un portorriqueño tiene una problemática diversa que la de un mexicano).

- No contamos (dicen que).

- [Somos] invisibles (dicen que). La razón de no contar y ser invisibles es que no votamos. Ello implica que el mensaje del raggaetón es oblicuo pues los ilegales, que no tienen derecho al voto, tampoco lo tienen en este momento. Se dirige a los conciudadanos de éstos que sí votan.

- Es fácil culparnos porque no votamos.

- Estamos aquí. Reafirmación de la presencia espacial.

- Todo va a cambiar (se supone, para nosotros).

- Marchamos. We did, pasado, marchas.

- Vamos a votar. Aplica la observación de 2.3.1.: los indocumentados no votan. 
- Vamos a elegir.

- Es tiempo. Se completa el aquí y el ahora: se necesita tomar la decisión ya, en estas elecciones primarias. Performativo, ilocucionario. Exhortatorio.

- ¿De qué cosa es tiempo? De algo diferente. Vaguedad, ambigüedad en "algo", pero hay que aprovechar la rima: un nuevo presidente, id est, Obama.

\subsection{Obama.}

- Es la esperanza. Ha llegado, es decir, antes no había. Obama es providencial. ¡Al fin!

- Es preparado. Autodefensivo. ¿Respecto a qué? ¿A Hillary o a la duda que puede haber sobre su preparación? No ontologiza sus otras debilidades electorales: raza $\mathrm{u}$ origen religioso. Preparado respecto a qué. En ciertos niveles académicos no tiene sentido decir que alguien es "preparado": se acostumbra expresar algo más específico, como "tiene doctorado" o "es licenciado en...". "Preparado" es una calificación que hace emerger a Obama de los no-preparados (los latinos son representantes bien establecidos de la no-preparación, ver nota 11). Se buscan, entonces, elementos identificatorios con una población de bajo nivel cultural (correlativo esto, a su vez, en general, al nivel económico y social).

- Diferenciación del candidato respecto a esa masa (es preparado). En su próxima pieza musical, se preparó en Chicago para una visión. En este caso, parece haberse preparado en la calle o en la vida, apelaciones válidas para la audiencia.

- Identificación con la candidata Hillary Clinton, que a sus grados académicos puede agregar un currículo de experiencia laboral exitosa más la de primera dama.

- Hay una doble función identificatoria/diferencial que juega en diversos planos. La noción es conocida por Ernesto Laclau: en Debates y Combates por un Nuevo Horizonte de la Política señala "la división de todo elemento significativo entre una dimensión equivalencial y una dimensión diferencial."

- Se infiere que Obama es agente del cambio para los latinos (nosotros). 
- Constituirá un nuevo [tipo] de presidente: ambiguo.

- Entiende, es alguien que entiende. ¿Qué? No se dice. Pero por identificación a un pueblo que le es conocido (aunque no pertenece a él racialmente ni socialmente) y por oposición, podría ser que Hillary no entendiera por su condición de blanca, primera dama, burguesa, etc.

2.4 Los demás (indefinido):

2.4.1 Acción: Decir (dicen):

2.4.1.1 Que no contamos. Victimización de los latinos buscando identificación grupal, seguramente.

2.4.1.2 Que todo el dinero va a la inmigración.

2.4.2 Interesantemente, parece que sólo quisiera predisponerlos, o aglutinarlos más con la identificación de víctimas de la incomprensión o maledicencia de los otros, pues no responde a la descalificación con argumentos o proclamas fuertes.

Podemos resumir lo anterior en una jerarquía:

1. Existe una gran nación (U. S. A.)

1.1 En ella estamos nosotros, la gente los latinos. Necesitamos un cambio (¿cuál?).

1.1.1 Hay un narrador/presentador que nos representa.

1.1.2 El resto de los latinos (nosotros, we; mexicanos, brasileños, etc.) no votamos, somos invisibles, nos culpan.

1.2 Y están también los demás, los que hablan de nosotros (los que dicen).

1.3 Obama: no es de nuestra gente, pero nos entiende. Está preparado, es nuestra esperanza y será un nuevo [¿tipo?] de presidente.

\subsection{SÍNTESIS DEL CANDIDATO OBAMA}

Se trata de una pieza de marketing político superficial que desarrolla un discurso identificatorio, vago, sin denuncias completas y menos propuestas completas, si alguna, que se apoya fuertemente en el recall de un candidato. Goebelsianamente emocional, sin 
compromise, ordinary language. Without crisppy differences. Not properly fuzzy but very warm indeed. Sin diferenciarse fuertemente ni del otro candidato, la señora Clinton, ni de los republicanos. ¿Disciplina partidaria o temor a suscitar una comparación que pueda desfavorecerlo? Sólo es autodefensivo respecto a su preparación. Insistirá en ello en su ranchera para el estado de Texas: se preparó en las calles de Chicago para una visión...

\subsection{HILLARY CLINTON}

El mensaje de la senadora es menos verboso. En efecto, el texto es de 125 palabras, utilizando un vocabulario: 72 palabras (texto sobre vocabulario: 73,61\%).

Los sustantivos ocurren 43 veces, es decir, son el 34,40\% del discurso. "Hillary" es el $29,27 \%$ del 100\% de los nombres. 9,60\% del discurso.

Verbos activos: 18 ocurrencias, 14,40\% del discurso, de los cuales, el tiempo pasado corresponde a 4 ocurrencias, $22,22 \%$ del total de verbos activos. Homogeneidad en la distribución.

El verbo "poder", inexistente en la canción de Obama, es, por lo menos, disémico en español: por un lado, significa posibilidad, "tal vez, a lo mejor"; por otro, tener fuerza para (power).

El spanglish es poco, pero no puede faltar: You got it! Take it away! Porcentualmente: $4,80 \%$ del texto, $6,94 \%$ del vocabulario.

También hay recalling 33\% del texto está dedicado a él vía repetición.

La ontología semántica que elucubramos es la siguiente:

1. Entorno: Indeterminado. Tácitamente, puede asumirse los Estados Unidos de Norteamérica.

2. Actuantes:

2.1 Narrador/presentador: Johnny Canales, conocido por su popular Johnny Canales Show.

2.1.1 Enlace entre sus amigos latinos y Hillary Clinton, que lo es de él y de ellos. Papel identificatorio.

2.1.2 Exhortatorio: no piensa dos veces para votar por Hillary. Apelación a la irreflexión (Goebels again, salvando las distancias, obviamente). 
2.2 Latınos. Amigos del narrador/presentador presentador que es latıno. Nosotros [tácito pero señalado por la conjugación].

2.2.1 Se requiere cambio. Vago.

2.2.2 "Tenemos que mejorar". Ambiguo.

2.3 Hillary Clinton.

2.3.1 No latina pero es nuestra amiga.

2.3.2 Sólo ella puede lograr la mejora que se necesita, whatever it be. Mesianismo.

2.3.3 Tiene experiencia porque "su esposo ya gobernó" (sic).

2.3.4 Conformará una presidencia fuerte. ¿Contra quién va eso? La actual administración es débil? ¿Será que Obama es débil?

2.3.5 Además, según la canción, participó en el gobierno de Clinton en plano de igualdad. Así "ellos [Hillary y Bill, y en ese orden pues se viene hablando de ella] hicieron algo juntos" que mejoró a los latinos. No sólo habría que especificar que es ese algo sino qué, realmente, hicieron juntos. Hay una presidencia, un gabinete ministerial, un congreso... Y una primera dama.

2.3.6 Habrá seguro médico para la gente (el uso no es neutro: en efecto, si bien es cierto que el sustantivo abarca a todos los humanos, por el alcance jurídico del presidente, podemos circunscribirlo a los habitantes de los Estados Unidos; pero la segunda aparición de "gente" es como "nuestra gente"; si no se advierte la ausencia del posesivo puede creerse que la gente de esta tierra son los latinos. Sin embargo, realmente, no enfatiza "a todos" ni promete nada específico a los latinos.

2.3.7 Economía mejor: no indica las vías. Acto de fe.

2.3.8 Leyes migratorias justas. Podrían ser beneficiosas pero su condición de justas no garantiza tal ventaja. ¿Justas para quién? ¿Qué significa justicia?

2.4 Bill Clinton. 
2.4.1 Está presente: Fuera de que su apellido se repite / veces, una vez el narrador/presentador dice: "por Clinton voto yo". Tomado a valor facial, la senadora Hillary no es Clinton.

2.4.2 Formó un equipo con su esposa Hillary.

2.5 Los republicanos.

2.5.1 No han podido terminar la guerra de Iraq. La distinción es clara y fuerte. Pero al no competir contra ellos, podría significar que Obama tampoco puede.

2.6 Otros: No hay.

\subsection{SÍNTESIS DE LA CANDIDATA CLINTON}

Hillary Clinton nos da una impresión de mayor seguridad, tal vez apoyada en las encuestas $^{27}$. No es autodefensiva. Sin embargo, su vaga promesa se apoya cuestionablemente en su condición de primera dama asignándose un rol en el gobierno que habría que justificar.

\subsection{RESUMEN COMPARATIVO}

Texto de Obama 52\% más corto que el de Clinton.

Texto de Obama $21 \%$ menos palabras que el de Clinton.

Repetición de Obama 118\% sobre $74 \%$ en Clinton.

Parecería que el texto de Clinton tuviese más información que el de Obama aunque menos recalling.

- Nombres en Obama: 20 ocurrencias, 27,85\%. “Obama": 60,61\% del 100\% de las ocurrencias. $16,88 \%$ de todo el discurso.

- Nombres en Clinton: 43 ocurrencias, 34,40\% del discurso. "Hillary" es el $29,27 \%$ del $100 \%$ de las ocurrencias. $9,60 \%$ de todo el discurso.

\footnotetext{
${ }^{27}$ Según Susan Minushkin, ya nombrada, Hillary Clinton tiene un 63\% de aceptación versus el 35\% de Barack Obama.
} 
- Verbos activos Obama: 59 ocurrencias, 25\% del discurso está ligado a la acción (prácticamente, todos los verbos son activos). Pero 10 de esas 59 ocurrencias $(16,95 \%$.).

- Verbos activos Clinton: 18 ocurrencias, 14,40\% del discurso. La distribución de las ocurrencias verbales es homogénea en Hillary.

- Adjetivos: 10 La adjetivación de Obama es pobre: 4,22\%. También casi inexistente en Hillary:

\section{Temporización:}

Presente Obama: mayoritario. Hay una explicitación del "aquí" y "ahora", pero al presente lo denuncia el tiempo verbal.

Presente Clinton: mayoritario.

Pasado Obama: mínimo (did), en spanglish y vinculado a los potenciales electores, no al candidato que no tiene historia que contar en ese sentido.

Pasado Clinton: Pasado: 4 ocurrencias, 22,22\% del total de verbos activos.

Futuro Obama: Mínimo, localizado en el verbo "ir": esto va a cambiar. Sólo una promesa abierta, indefinida.

Futuro Clinton: Inexistente, de modo explícito o directo. "Puede darle", sin embargo, presentizado, debe inevitablemente fijarse en el futuro si la candidata gana.

\section{Spanglish:}

Obama: 4,22\% del texto.

Clinton: $4,80 \%$ del texto.

Comparativamente, menor uso hace Obama.

\section{Recalling:}

Mayor en Obama, 46\% que en Hillary, 33\%.

\section{Debilidades:}

Autodefensivo. Sólo en Obama.

Apoyo en terceros. Sólo en Hillary Clinton. No menciona su trabajo senatorial, aunque tampoco Obama, y éste parecería requerirlo más. ¿Será que la labor de ambos es irrelevante, al menos para convocar voluntades electorales hispanas? 
Como conclusión, si nos atenemos por estas piezas musicales, la situación de los hispanos no parece que pueda variar. Son aproximados desde sus carencias identificatorias mediante un mensaje que propaga -formal y conceptualmente- su deficiente nivel cultural. Se los incita a votar por candidatos cuyas características o programas son, si acaso, mínimamente expuestos, cuando no dudosos. Se procura, sin mucho esfuerzo intelectual, asociarlos como masa por la vía emocional a Obama y a la señora Clinton. Se utilizan técnicas de mercadeo valiosas para la promoción de productos masivos como jabón de tocador o detergentes.

\section{NOTA IMPORTANTE}

Este trabajo fue realizado antes de que el candidato Obama ganara las elecciones primarias del Partido Demócrata Norteamericano. Obama deberá ahora, frente al candidato republicano McCain, volver otra vez a la contienda. El voto de 13 millones de votantes latinos inscritos ${ }^{28}$ no es una cifra despreciable, particularmente para quien no ganó las primarias precisamente por el voto latino. Las encuestas, no obstante, lo colocan ganando en este sector, frente a McCain, con alrededor de un $60 \%$. Los vínculos de Obama con la comunidad latina son percibidos como muy débiles. Para corregir eso, pondrá los pies en Latinoamérica, por primera vez, antes de las elecciones: su destino es México "lindo y querido". "Pos que" le vaya bien...

Medellín, 5 de julio de 2008.

\footnotetext{
${ }^{28}$ Oppenheimer Andrés (2008). “Obama y los latinos” en Cambio, N| 782, 26 de julio, p. 70. Bogotá: Editorial El Tiempo.
} 


\section{Apéndices}

\section{Barack Obama}

\section{¿Cómo Se Dice... Cómo Se llama? (OBAMA, OBAMA)}

\section{Reggaetón}

Oye mi gente éste es un hombre preparado...

La esperanza ha llegado.

¿Cómo se dice... Cómo se llama?

OBAMA! OBAMA! (Repeat four times)

Dicen que no contamos...

Invisibles porque no votamos...

Pero aquí estamos y todo esto va a cambiar...

We did the marchas y ahora vamos a votar.

Listen to me gente, es tiempo para algo diferente...

What we need is un nuevo presidente...

¿Cómo se dice ... Cómo se llama?

OBAMA! OBAMA! (Repeat two times)

Los mexicanos, ¿cómo se llama?

OBAMA! OBAMA!

Puertorriqueños, ¿cómo se llama?

OBAMA! OBAMA!

Los peruanos, ¿cómo se llama?

OBAMA! OBAMA!

En esta gran nación ya no existe una buena educación,
Dicen todo el dinero va a la inmigración

Es fácil culpar al que no vota

El gigante latino está que brota.

¡Despierta! Vamos a elegir a quien de veras entienda...

¿Cómo se dice... Cómo se llama?

OBAMA! OBAMA! (Repeat four times)

Los colombianos, cómo se llama?

OBAMA! OBAMA!

Dominicanos, cómo se llama?

OBAMA! OBAMA!

Los cubanos, ¿cómo se llama?

OBAMA! OBAMA!

Los brasileros, ¿cómo se llama?

OBAMA! OBAMA!

Salvadoreños, ¿cómo se llama?

OBAMA! OBAMA!

Latinos!!! La esperanza ha llegado.

¿Cómo se dice... Cómo se llama? (Repeat) ${ }^{29}$

29 (C) 2007. Nueva Vista Media, Inc. AII Rights Reserved. Music and lyrics for "Cómo Se Dice ... Cómo Se Llama (OBAMA, OBAMA) are copywritten and may not be used without the expressed written consent of Nueva Vista Media, Inc. 


\begin{tabular}{|c|c|}
\hline faranta & a nuste \\
\hline $\mathrm{a}$ & 5 \\
\hline ahora & 1 \\
\hline al & 1 \\
\hline algo & 1 \\
\hline aquí & 1 \\
\hline brasileros & 1 \\
\hline brota & 1 \\
\hline buena & 1 \\
\hline cambiar & 1 \\
\hline colombianos & 1 \\
\hline cómo & 30 \\
\hline contamos & 1 \\
\hline cubanos & 1 \\
\hline culpar & 1 \\
\hline de & 1 \\
\hline despierta & 1 \\
\hline dice & 10 \\
\hline dicen & 2 \\
\hline did & 1 \\
\hline diferente & 1 \\
\hline dinero & 1 \\
\hline dominicanos & 1 \\
\hline educación & 1 \\
\hline el & 2 \\
\hline elegir & 1 \\
\hline entienda & 1 \\
\hline es & 3 \\
\hline esperanza & 2 \\
\hline esta & 1 \\
\hline
\end{tabular}

\begin{tabular}{|c|c|}
\hline faranea & a \\
\hline está & 1 \\
\hline estamos & 1 \\
\hline éste & 1 \\
\hline esto & 1 \\
\hline existe & 1 \\
\hline fácil & 1 \\
\hline gente & 2 \\
\hline gigante & 1 \\
\hline gran & 1 \\
\hline ha & 2 \\
\hline hombre & 1 \\
\hline inmigración & 1 \\
\hline invisibles & 1 \\
\hline is & 1 \\
\hline la & 3 \\
\hline latino & 1 \\
\hline latinos & 1 \\
\hline listen & 1 \\
\hline llama & 18 \\
\hline llegado & 2 \\
\hline los & 5 \\
\hline marchas & 1 \\
\hline me & 1 \\
\hline mexicanos & 1 \\
\hline $\mathrm{mi}$ & 1 \\
\hline nación & 1 \\
\hline need & 1 \\
\hline no & 4 \\
\hline nuevo & 1 \\
\hline
\end{tabular}

\begin{tabular}{|c|c|}
\hline taranta & a \\
\hline OBAMA & 40 \\
\hline oye & 1 \\
\hline para & 1 \\
\hline pero & 1 \\
\hline peruanos & 1 \\
\hline porque & 1 \\
\hline preparado & 1 \\
\hline presidente & 1 \\
\hline $\begin{array}{l}\text { puertorriqueñ } \\
\text { os }\end{array}$ & 1 \\
\hline que & 3 \\
\hline quien & 1 \\
\hline salvadoreños & 1 \\
\hline se & 28 \\
\hline the & 1 \\
\hline tiempo & 1 \\
\hline to & 1 \\
\hline todo & 2 \\
\hline un & 2 \\
\hline una & 1 \\
\hline va & 2 \\
\hline vamos & 2 \\
\hline veras & 1 \\
\hline vota & 1 \\
\hline votamos & 1 \\
\hline votar & 1 \\
\hline we & 2 \\
\hline What & 1 \\
\hline y & 2 \\
\hline ya & 1 \\
\hline
\end{tabular}


Clinton ... you got it! Take it away! Eso!

Hillary, Hillary Clinton

Necesitamos un cambio tenemos que mejorar

Y hay sólo una candidata que sí lo puede lograr

Ella tiene la experiencia su esposo ya gobernó

y con lo que hicieron juntos nuestra gente mejoró.

Hillary, Hillary Clinton (por ella voto yo)

Hillary, Hillary Clinton (por ella voto yo)

Una Presidenta fuerte, puede terminar la guerra

Y darle seguro medica a la gente de esta tierra

Leyes migratorias justas y la economía mejor

No me lo pienso dos veces, por Hillary voto yo.

Hillary, Hillary Clinton (por ella voto yo)

Hillary, Hillary Clinton (por ella voto yo)

Por Clinton voto yo.

Indexverborum

\begin{tabular}{|l|l|}
\hline Palabra & Cuenta \\
\hline a & 2 \\
\hline amiga & 1 \\
\hline amigos & 1 \\
\hline away & 1 \\
\hline cambio & 1 \\
\hline Canales & 1 \\
\hline canción & 1 \\
\hline candidata & 1 \\
\hline Clinton & 7 \\
\hline con & 1 \\
\hline darle & 1 \\
\hline de & 1 \\
\hline dedicar & 1 \\
\hline dos & 1 \\
\hline economía & 1 \\
\hline ella & 5 \\
\hline
\end{tabular}

\begin{tabular}{|l|l|}
\hline Palabra & Cuenta \\
\hline esta & 2 \\
\hline experiencia & 1 \\
\hline fuerte & 1 \\
\hline gente & 2 \\
\hline gobernó & 1 \\
\hline got & 1 \\
\hline guerra & 1 \\
\hline habla & 1 \\
\hline hay & 1 \\
\hline hicieron & 1 \\
\hline Hillary & 12 \\
\hline it & 2 \\
\hline Johnny & 1 \\
\hline juntos & 1 \\
\hline justas & 1 \\
\hline la & 4 \\
\hline
\end{tabular}

\begin{tabular}{|l|l|}
\hline Palabra & Cuenta \\
\hline leyes & 1 \\
\hline lo & 3 \\
\hline lograr & 1 \\
\hline me & 1 \\
\hline médico & 1 \\
\hline mejor & 1 \\
\hline mejorar & 1 \\
\hline mejoró & 1 \\
\hline migratorias & 1 \\
\hline mis & 1 \\
\hline necesitamos & 1 \\
\hline no & 1 \\
\hline nuestra & 2 \\
\hline pienso & 1 \\
\hline por & 6 \\
\hline presidenta & 1 \\
\hline
\end{tabular}

\begin{tabular}{|l|l|}
\hline Palabra & Cuenta \\
\hline quiero & 1 \\
\hline seguro & 1 \\
\hline sí & 1 \\
\hline sólo & 1 \\
\hline su & 1 \\
\hline take & 1 \\
\hline tenemos & 1 \\
\hline terminar & 1 \\
\hline tiene & 1 \\
\hline tierra & 1 \\
\hline un & 1 \\
\hline una & 2 \\
\hline veces & 1 \\
\hline voto & 6 \\
\hline y & 4 \\
\hline ya & 1 \\
\hline
\end{tabular}

${ }^{30}$ Escrito por Walter Sur. 
- Ball Michael S. y Smith Gregory W. S. (1992) Analyzing visual data qualitative research series. Newbury Park: Sage.

- Beserra Bernadete (2003). Brazilian Immigrants in the United States: Cultural Imperialism and Social Class. New York: LFB Scholarly Publishing LLC. ISBN: 1-931202-68-0.

- Hall Stuart (1996). Questions of Cultural Identities. London: Sage Publications.

- Henley Paul (2000). "Cine etnográfico: tecnología práctica y teoría antropológica." Desacatos 8: 17-36.

- Laclau Ernesto, Mouffe Chantal (1985). Hegemony and Socialist Strategy: Toward a radical democratic politics. London: Verso.

- Laclau Ernesto (1987). "Populismo y transformación del imaginario político en América Latina", Boletín de Estudios Latinoamericanos y del Caribe, n 42, pp. 25-38.

- Laclau Ernesto (2005). La razón populista. Buenos Aires: Fondo de Cultura Económica.

- Laclau Ernesto (2006). "La deriva populista y la centroizquierda latinoamericana" en Revista de la CEPAL, Santiago de Chile, Agosto de 2006, No 89, 56-61.

- Minushkin Susan (2008). The Hispanic Vote in the 2008 Democratic Presidential Primaries, Pew Hispanic Center. http://pewhispanic.org/files/reports/86.pdf. Actualizado: 07/03/2008.

- Padrón Guillén José (1989). Un enfoque ampliado de los materiales instruccionales en videotape: la concepción no audiovisual del audiovisual. Informe de Investigaciones Educativas. Vol. III. No 2.

- Patruyo Thanalí (2006). “Comentarios a propósito de la visita de Ernesto Laclau. La razón populista: aproximación a los retos teóricos de un modelo redefinido" en Cuadernos del CENDES, Año 23, Nº3, Tercera Época, Septiembre-Diciembre 2006, 169-176.

- Roca Lourdes (2004). La imagen como Fuente: Una construcción de la Investigación Social. México: Razón y Palabra.

- Vilches Lorenzo (1988). La lectura de la imagen. Prensa, cine, televisión. Barcelona: Paidós.

- Weber Max (1983). Economía y sociedad. Esbozo de sociología comprensiva. México: Fondo de Cultura Económica.

- Worth Sol (1969). The development of a semiotic of film en Larry Gross (ed.) Studying Visual communication, 185-199) Philadelphia: University of Pennsylvania Press. 